\title{
Numerical and Experimental Investigations on the Meshing Model Choice of a NACA2415 Airfoil Wind Turbine Placed in an Open Wind Tunnel
}

Zied Driss ${ }^{1 *}$, Tarek Chelbi ${ }^{1}$, Walid Barhoumi ${ }^{1}$, Ahmed Kaffel ${ }^{2}$ and Mohamed Salah Abid ${ }^{1}$

${ }^{1}$ Laboratory of Electro-Mechanic Systems (LASEM), National School of Engineers of Sfax (ENIS), University of Sfax, B.P. 1173, Road Soukra 3038, Sfax, Tunisia, Africa 2University of Maryland College Park, MD 20742, USA

\begin{abstract}
In this work, we are interested on the numerical and experimental investigations of a NACA2415 airfoil wind turbine placed in an open wind tunnel. The study of the meshing effect on the numerical results was developed using a commercial CFD code based on the resolution of the Navier-Stokes equations in conjunction with the standard k- $\varepsilon$ turbulence model. These equations were solved by a finite volume discretization method. The developed numerical results are compared with experimental results to choose the adequate meshing.
\end{abstract}

Keywords: Wind turbine; NACA2415; Wind tunnel; Meshing; Modeling; CFD

\section{Nomenclature}

C: Width, $\mathrm{m}$

$\mathrm{C}_{1 \varepsilon}$ : Constant of the $\mathrm{k}-\varepsilon$ turbulence model, dimensionless

$\mathrm{C}_{2 \varepsilon}$ : Constant of the $\mathrm{k}-\varepsilon$ turbulence model, dimensionless

$\mathrm{C}_{\mu}$ : Constant of the $\mathrm{k}-\varepsilon$ turbulence model, dimensionless

$\mathrm{F}_{\mathrm{i}}$ : Force components, $\mathrm{N}$

$\mathrm{G}_{\mathrm{k}}$ : Production term of turbulence, $\mathrm{kg} \cdot \mathrm{m}^{-1} \cdot \mathrm{s}^{-3}$

$\mathrm{k}$ : Turbulent kinetic energy, J.kg-1

L: Length, $\mathrm{m}$

p: Pressure, $\mathrm{Pa}$

$\mathrm{R}$ : Rotor radius, $\mathrm{m}$

Re: Reynolds number

$\mathrm{t}$ : Time, $\mathrm{s}$

$\mathrm{u}_{\mathrm{i}}$ : Velocity components, $\mathrm{m} \cdot \mathrm{s}^{-1}$

$\mathrm{u}_{\mathrm{i}}^{\prime}$ : Fluctuating velocity components, $\mathrm{m} \cdot \mathrm{s}^{-1}$

V : Magnitude velocity, $\mathrm{m} \cdot \mathrm{s}^{-1}$

$\mathrm{x}_{\mathrm{i}}$ : Cartesian coordinate, $\mathrm{m}$

$\mathrm{x}$ : Cartesian coordinate, $\mathrm{m}$

$\mathrm{y}$ : Cartesian coordinate, $\mathrm{m}$

$\mathrm{z}$ : Cartesian coordinate, $\mathrm{m}$

$\beta$ : Wedging angle, ${ }^{\circ}$

$\varepsilon:$ Dissipation rate of the turbulent kinetic energy, W. $\mathrm{kg}^{-1}$

$\mu$ : Dynamic viscosity, Pa.s

$\mu_{\mathrm{t}}$ : Turbulent viscosity, Pa.s

$\rho:$ Density, kg.m ${ }^{-3}$

$\sigma_{\mathrm{k}}$ : Constant of the k- $\varepsilon$ turbulence model

$\sigma_{\varepsilon}$ : Constant of the k- $\varepsilon$ turbulence model

$\delta_{\mathrm{ij}}: \quad$ Kronecker delta function, dimensionless

\section{Introduction}

To prepare a truly sustainable development, the community recommends increasing the share of renewable resources for electricity generation. The production of electricity by wind turbines is playing a major role. In this context, many scientists have examined the effects of wind turbines parameters design. For example, Hirahara et al. [1] developed a unique and very small wind turbine with a diameter of $500 \mathrm{~mm}$ and a small aspect ratio for wide use in urban space. The basic performance was tested for various free stream and load resistance. The airflow around the turbine was investigated using a particle image velocimetry (PIV). Wright and Wood [2] showed that the acceleration and deceleration of the rotor at speeds below its controlled maximum speed for a range of wind speeds were calculated and compared with data. Schreck and Robinson [3] showed that wind turbine blade aerodynamic phenomena can be broadly categorized according to the operating state of the machine, and two particular aerodynamic phenomena assume crucial importance. At zero and low rotor yaw angles, increasing rotation determines blade aerodynamic response. At moderate to high yaw angles, dynamic stall dominates blade aerodynamic. The main goal of the Mirzaei et al. [4] investigation was to understand the flow field structure of the separation bubble formed on NLF-0414 airfoil with glaze-ice accretions using CFD and hot-wire anemometry and comparing these results with previous researches performed on NACA 0012 airfoil. Hu et al. [5] showed that Coriolis and centrifugal forces play important roles in 3D stall-delay. At the root area of the blade, where the high angles of attack occur, the effect of the Coriolis and centrifugal forces is dominant. Thus, it shows apparent stall-delay phenomenon at the inner part of the blade. However, by increasing the Reynolds number, the separation position has a stronger effect than by increasing the Coriolis and centrifugal forces. Sicot et al. [6] investigated the aerodynamic properties of a wind turbine airfoil.

*Corresponding author: Zied Driss, Laboratory of Electro-Mechanic Systems (LASEM), National School of Engineers of Sfax (ENIS), University of Sfax, B.P. 1173, Road Soukra 3038, Sfax, Tunisia, Africa, E-mail: zied.driss@enis.tn

Received April 28, 2015; Accepted June 30, 2015; Published July 15, 2015

Citation: Driss Z, Chelbi T, Barhoumi W, Kaffel A, Abid MS (2015) Numerical and Experimental Investigations on the Meshing Model Choice of a NACA2415 Airfoil Wind Turbine Placed in an Open Wind Tunnel. J Phys Math 6: 141 doi:10.4172/2090-0902.1000141

Copyright: (C) 2015 Driss Z, et al. This is an open-access article distributed under the terms of the Creative Commons Attribution License, which permits unrestricted use, distribution, and reproduction in any medium, provided the original author and source are credited. 
Particularly, they studied the influence of the inflow turbulence level (from $4.5 \%$ to $12 \%$ ) and of the rotation on the stall mechanisms in the blade. A local approach was used to study the influence of these parameters on the separation point position on the suction surface of the airfoil, through simultaneous surface pressure measurements around the airfoil. Tahar Bouzaher [7] studied the flow around a NACA2415 airfoil, with an $18^{\circ}$ angle of attack, and flow separation control using a rod. It involves putting a cylindrical rod-upstream of the leading edge- in vertical translation movement in order to accelerate the transition of the boundary layer by interaction between the rod wake and the boundary layer. The rod movement is reproduced using the dynamic mesh technique and an in-house developed UDF (User Define Function). Results showed a substantial modification in the flow behavior and a maximum drag reduction of $61 \%$.

Despite the numerous papers already devoted to this subject, studying the aerodynamic characteristics of the horizontal axis NACA2415 airfoil type wind turbine is still needed. The present work is concerned to study the meshing effect on the numerical results developed using the software "Solid Works Flow Simulation". The developed numerical results are compared with experimental results conducted on an open wind tunnel to choose the adequate numerical model.

\section{Experimental Device}

The considered wind turbine is a horizontal axis with a NACA2415 airfoil type placed in the test section of the wind tunnel. The wind tunnel is an open type and provides a stable and uniform air flow in the test section through a downstream vacuum. The compounds of the wind tunnel are presented in Figure 1. The wind turbine consists of three adjustable blades of a length $\mathrm{L}=110 \mathrm{~mm}$ and a width $\mathrm{C}=45 \mathrm{~mm}$. The rotor radius of the turbine is equal to $\mathrm{R}=157 \mathrm{~mm}$. The wedging angle is measured between the rotation plane of the wind turbine and the chord; it's equal to $\beta=30^{\circ}$ (Figure 2). To develop various experimental tests required at the laboratory scale, we used a specific instrumentation [8-10] (Table 1).

\section{Anemometer}

To determine the velocity profiles in different directions preselected in the test section of the wind tunnel, the anemometer type AM 4204 has been used (Figure 3). This anemometer measures wind speed in different positions with a range variation between 0.2 and 20 $\mathrm{m} . \mathrm{s}^{-1}$ and a resolution reaching $0.1 \mathrm{~m} . \mathrm{s}^{-1}$. The different characteristics of this anemometer are summarized in Table 2.

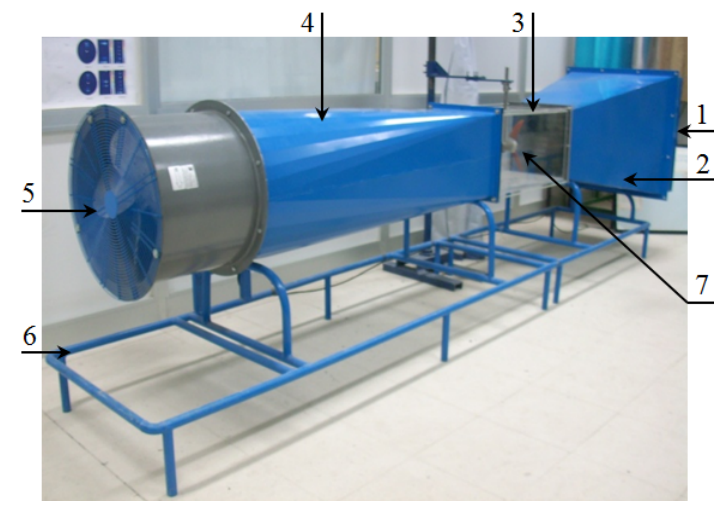

Figure 1: Compounds of the open wind tunnel.
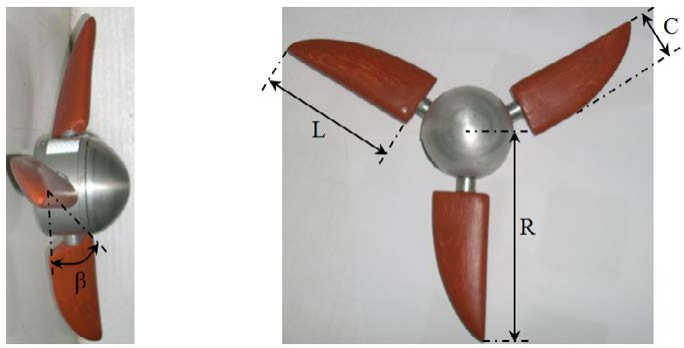

Figure 2: Geometric parameters of the wind turbine.

\begin{tabular}{|c|c|}
\hline 1 & Tranquilization chamber \\
\hline 2 & Collector \\
\hline 3 & Test section \\
\hline 4 & Diffuser \\
\hline 5 & Ventilation chamber \\
\hline 7 & Support \\
\hline
\end{tabular}

Table 1: Compounds of the open wind tunnel.

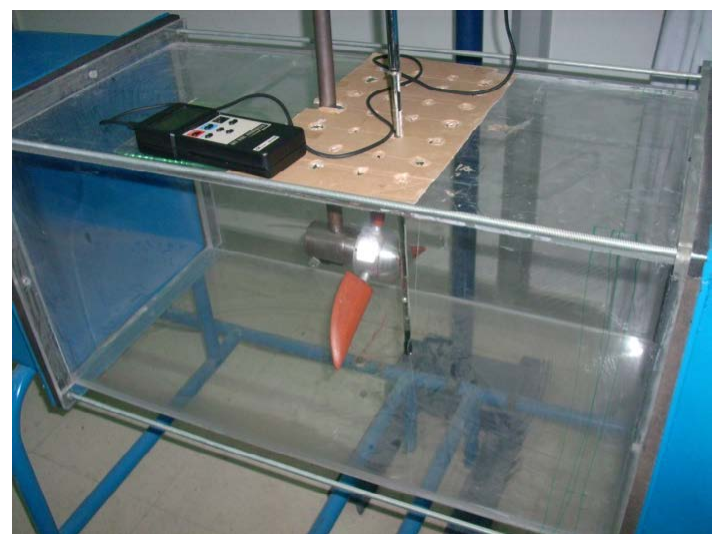

Figure 3: Wind speed measuringusing the anemometer type AM 4204.

\begin{tabular}{|c|c|}
\hline Description & Anemometer type AM 4204 \\
\hline Maker & Lutron \\
\hline Probe type & telescopic \\
\hline Measurement parameters & Air velocity, temperature, gas flow \\
\hline Resolution & $\begin{array}{c}\text { Air velocity } 0.1 \mathrm{~m} . \mathrm{s}^{-1} \\
\text { Temperature } 0.1^{\circ} \mathrm{C}\end{array}$ \\
\hline Precision & $\begin{array}{c}\text { Air velocity } 5 \% \\
\text { Temperature } \pm 0.8^{\circ} \mathrm{C}\end{array}$ \\
\hline Measuring range & Velocity $0.1{\mathrm{~m} . \mathrm{s}^{-1}}^{\circ}$ \\
& Temperature from $-20^{\circ} \mathrm{C}$ to $+70^{\circ} \mathrm{C}$ \\
\hline
\end{tabular}

Table 2: Characteristics of the anemometer.

\section{Tachometer}

Figure 4 presents the tachometer type CA1725. This device is used for measuring the rotation speed of the rotor. The optical sensor can provide results without disrupting the movement of the rotor. Tachometer features are summarized in Table 3.

\section{Numerical Model}

The software "Flow Simulation" is based on solving Navier-Stokes equations with a finite volume discretization method. The technique 


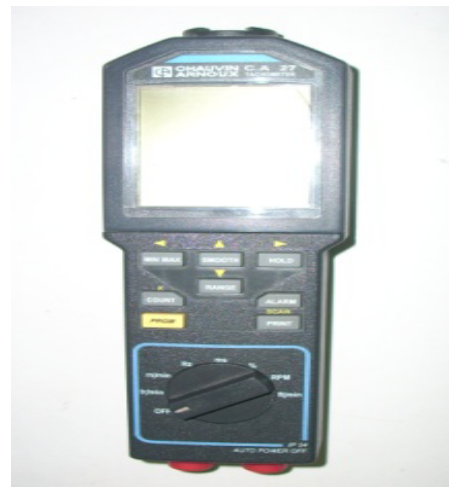

Figure 4: Tachometer type CA1725.

\begin{tabular}{|c|c|}
\hline Description & Tachometer type CA1725 \\
\hline Speed range & 6 to $100000 \mathrm{tr} / \mathrm{min}$ \\
\hline Resolution & 0.0006 to 6 according size \\
\hline Precision & $10^{-4}$ reading \pm 6 points \\
\hline Supply & $9 \mathrm{~V}$ \\
\hline Autonomy & 250 steps of 5 min with optical sensor \\
\hline Dimension & $21 \times 72 \times 47 \mathrm{~mm}$ \\
\hline Weight & $250 \mathrm{~g}$ \\
\hline
\end{tabular}

Table 3: Characteristics of the tachometer.

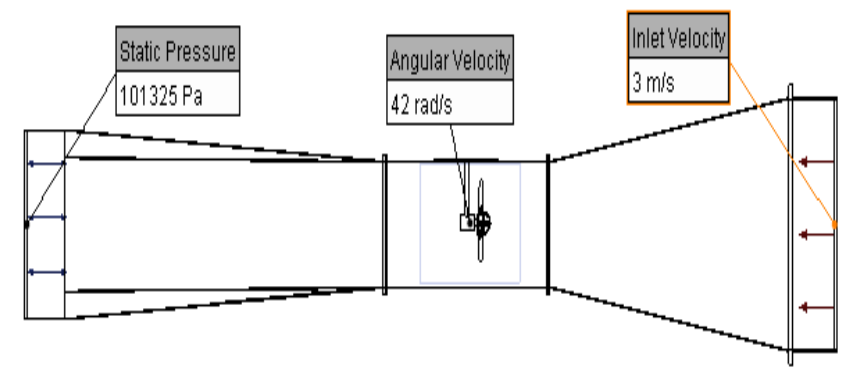

Figure 5: Boundary Conditions

consists in dividing the computational domain into elementary volumes around each node in the grid; it ensures continuity of flow between nodes. The spatial discretization is obtained by following a procedure for tetrahedral interpolation scheme. As for the temporal discretization, the implicit formulation is adopted. The transport equation is integrated over the control volume [10-13].

\section{Computational domain and boundary conditions}

Using the software "Solid Works", the computational domain is defined by the interior volume of the wind tunnel blocked by two planes: the first one is in the tranquillization chamber entry and the second one is in the exit of the diffuser (Figure 5). The boundary conditions are very important and require a lot of precision for an exact description of the problem in order to get satisfactory results. The velocity inlet, measured in the tranquilization chamber, is equal to $\mathrm{V}=3 \mathrm{~m} \cdot \mathrm{s}^{-1}$. The static pressure of the air flow through the drive section is made at the atmospheric conditions. For this reason, the pressure outlet is set equal to $\mathrm{p}=101325 \mathrm{~Pa}$. Around the wind turbine, a rotating area was considered with an angular velocity equal to $\Omega=42 \mathrm{rad}^{-1}{ }^{-1}$.
In these conditions, the Reynolds number is equal to $R e=265403$. For the initial conditions, we choose null values for all parameters of the computational domain.

\section{Navier-stokes equations}

The equations that govern the movement of fluids are often called the Navier-Stokes equations. Most of these equations involve a process of time-averaging. When turbulence is included, the transported quantity is assumed to be the sum of an average and a fluctuating component [10-11].

The continuity equation is written as follows:

$$
\frac{\partial \rho}{\partial t}+\frac{\partial\left(\rho u_{i}\right)}{\partial x_{i}}=0
$$

The momentum equations are written as follows:

$$
\frac{\partial\left(\rho \mathrm{u}_{\mathrm{i}}\right)}{\partial \mathrm{t}}+\frac{\partial\left(\rho \mathrm{u}_{\mathrm{i}} \mathrm{u}_{\mathrm{j}}\right)}{\partial \mathrm{x}_{\mathrm{j}}}=-\frac{\partial \mathrm{p}}{\partial \mathrm{x}_{\mathrm{i}}}+\frac{\partial}{\partial \mathrm{x}_{\mathrm{j}}}\left[\mu\left(\frac{\partial \mathrm{u}_{\mathrm{j}}}{\partial \mathrm{x}_{\mathrm{j}}}+\frac{\partial \mathrm{u}_{\mathrm{j}}}{\partial \mathrm{x}_{\mathrm{i}}}-\frac{2}{3} \delta_{i j} \frac{\partial \mathrm{u}_{\mathrm{i}}}{\partial \mathrm{x}_{\mathrm{i}}}\right)\right]+\frac{\partial\left(-\rho \overline{\mathrm{u}_{\mathrm{i}} \mathrm{u}_{\mathrm{j}}^{\prime}}\right)}{\partial \mathrm{x}_{\mathrm{j}}}+\mathrm{F}_{\mathrm{i}}
$$

To close the system of equations, we have used the k- $\varepsilon$ turbulence model. This model has been used in different anterior works and satisfactory results were obtained [12-15]. It consists on the transport equation of the turbulent kinetic energy $\mathrm{k}$ and the transport equation of the dissipation rate of the turbulent kinetic energy $\varepsilon$ :

$$
\begin{aligned}
& \frac{\partial(\rho \mathrm{k})}{\partial \mathrm{t}}+\frac{\partial\left(\rho \mathrm{u}_{\mathrm{i}} \mathrm{k}\right)}{\partial \mathrm{x}_{\mathrm{i}}}=\frac{\partial}{\partial \mathrm{x}_{\mathrm{j}}}\left[\left(\mu+\frac{\mu_{\mathrm{t}}}{\sigma_{\mathrm{k}}}\right) \frac{\partial \mathrm{k}}{\partial \mathrm{x}_{\mathrm{j}}}\right]+\mathrm{G}_{\mathrm{k}}-\rho \varepsilon \\
& \frac{\partial(\rho \varepsilon)}{\partial \mathrm{t}}+\frac{\partial\left(\rho \mathrm{u}_{\mathrm{i}} \varepsilon\right)}{\partial \mathrm{x}_{\mathrm{i}}}=\frac{\partial}{\partial \mathrm{x}_{\mathrm{j}}}\left[\left(\mu+\frac{\mu_{\mathrm{t}}}{\sigma_{\varepsilon}}\right) \frac{\partial \varepsilon}{\partial \mathrm{x}_{\mathrm{j}}}\right]+C_{1 \varepsilon} \frac{\varepsilon}{\mathrm{k}} G_{k}-C_{2 \varepsilon} \rho \frac{\varepsilon^{2}}{k}
\end{aligned}
$$

The hypothesis introduces also the turbulent viscosity $\mu_{t}$. This term is derived from both $\mathrm{k}$ and $\varepsilon$, and involves a constant taken from experimental data:

$$
\mu_{\mathrm{t}}=\rho \mathrm{C}_{\mu} \frac{\mathrm{k}^{2}}{\varepsilon}
$$

To summarize the solution process for the $\mathrm{k}-\varepsilon$ model, transport equations are solved for the turbulent kinetic energy $k$ and the dissipation rate of the turbulent kinetic energy $\varepsilon$. The solutions for $\mathrm{k}$ and $\varepsilon$ are used to compute the turbulent viscosity $\mu_{\mathrm{t}}$. Using these results, the Reynolds stresses can be computed for substitution into the momentum equations. Once the momentum equations have been solved, the new velocity components are used to update the turbulence generation term. This process is repeated until the convergence of the solutions [12-15].

\section{Meshing}

The goal of this section is to demonstrate various meshing capabilities of "Flow Simulation" allowing us to better adjust the computational mesh to the problem at hand. Although the automatically generated mesh is usually appropriate, intricate problems with thin or small, but important, geometrical and physical features can result in extremely high number of cells, for which the computer memory is too small. In such cases flow simulation options allow us to manually adjust the computational mesh to the solved problem's features to resolve them better. The geometry can be resolved reasonably well. However, if we generate the mesh and zoom in a thin region, we will see that it may still unresolved. In order to resolve these regions properly, we will use the local initial mesh option. The local initial mesh option allows us to specify an initial mesh in a local region of the computational domain to better resolve the model geometry and flow peculiarities 
in this region. The local region can be defined by a component of the assembly, disabled in the component control dialogue box, or specified by selecting a face, edge or vertex of the model. Local mesh settings are applied to all cells intersected by a component, face, edge, or a cell enclosing the selected vertex. The local mesh settings do not influence the basic mesh but are basic mesh sensitive: all refinement levels are set with respect to the basic mesh cell. To refine the mesh only in a specific region and avoid excessive splitting of the mesh cells in other parts of the model, we apply a local initial mesh at the component surrounding this region. The component is created specially to specify the local initial mesh. The settings on the narrow channels tab control the mesh refinement in the model's flow passages. Characteristic number of cells across a narrow channel box specifies the number of initial mesh cells (including partial cells) that flow simulation will try to set across the model's flow passages in the direction normal to solid/fluid interface. If possible, the number of cells across narrow channels will be equal to the specified characteristic number. Otherwise, it will be close to the characteristic number. If this condition is not satisfied, the cells lying in this direction will be split to satisfy the condition.

In this application, we are interested on the study of the mesh resolution's effect. In fact, we are going to change the size of the mesh and compare the results with the values of the velocity collected from the test section obtained experimentally. Figures 6 and 7 show the 2D

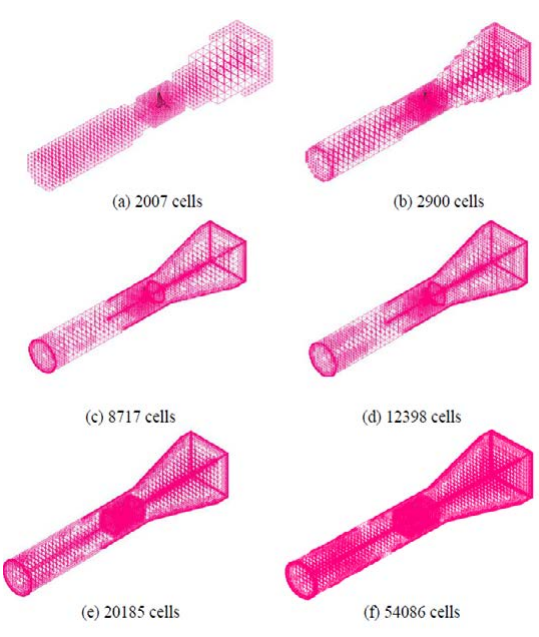

Figure 6: 3D view of the meshing.

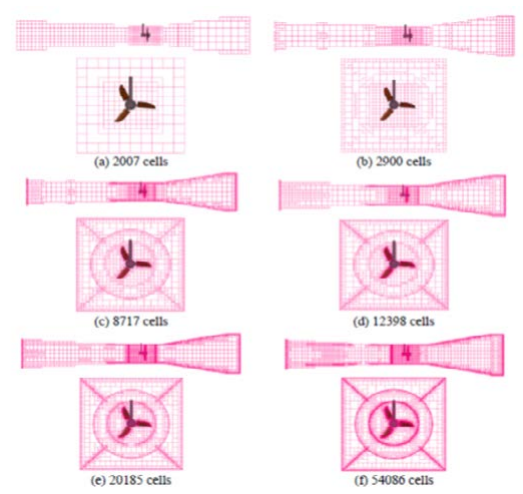

Figure 7: 2D view of the meshing.

\begin{tabular}{|c|c|c|c|c|}
\hline Cases study & Cells number & $\begin{array}{c}\text { Resolution } \\
\text { time (h:m:s) }\end{array}$ & \multicolumn{2}{|c|}{ Velocity $\left.\mathbf{( m . s}^{-1}\right)$} \\
\cline { 3 - 4 } & & $0: 1: 50$ & 17.47 & \multirow{2}{*}{13.94} \\
\hline 1 & 2007 cells & Numerical & Experimental \\
\hline 2 & 2900 cells & $0: 2: 00$ & 16.18 & \\
\hline 3 & 8771 cells & $0: 9: 32$ & 15.15 & \\
\hline 4 & 12398 cells & $0: 13: 41$ & 14.88 & \\
\hline 5 & 20185 cells & $0: 21: 37$ & 15.97 & \\
\hline 6 & 54086 cells & $1: 07: 27$ & 13.34 & \\
\hline
\end{tabular}

Table 4: Mesh selection criterium.
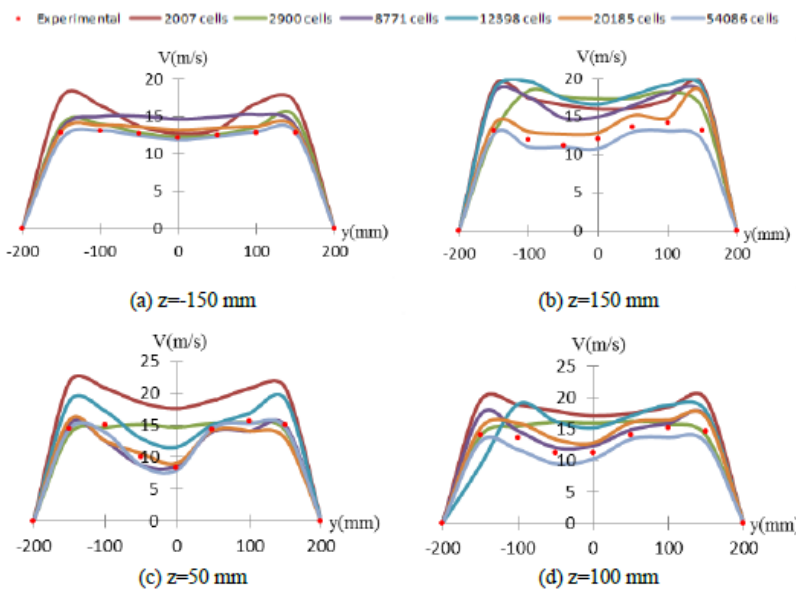

(b) $\mathrm{z}=150 \mathrm{~mm}$

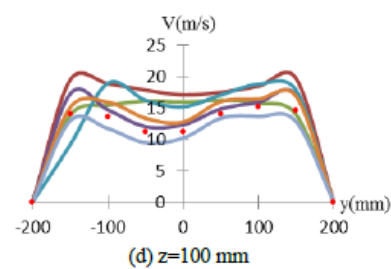

Figure 8: Velocity profiles.

and the $3 \mathrm{D}$ views of the meshing. In particular, we have chosen to study six meshes. The first case to be treated corresponds to a cell size of 200 $\mathrm{mm}$. The second case corresponds to a cell size of $100 \mathrm{~mm}$. The third case corresponds to a cell size of $20 \mathrm{~mm}$. The fourth case corresponds to a cell size of $15 \mathrm{~mm}$. The fifth case corresponds to a cell size of 10 $\mathrm{mm}$. The latter one corresponds to a cell of $5 \mathrm{~mm}$. In these cases, the number of cells is respectively equal to $2007,2900,8717,12398,20185$ and 54086 cells; which corresponds to a coarse mesh in the first case and a refined mesh in the sixth case.

\section{Comparison Between Numerical and Experimental Results}

In this work, computer investigations are carried out to study the flow field developing around a NACA2415 airfoil wind turbine. The models tested are implemented in the software "Solid Works Flow Simulation" which uses a finite volume scheme. The numerical results are compared with experiments conducted on an open wind tunnel to validate the numerical results. This will help improving the aerodynamic efficiency in the design of packaged installations of the NACA2415 airfoil type wind turbine. Table 4 presents the resolution time and the velocity value measured in the test section for the treated cases. According to these results, it has been noted that the velocity value obtained for the fifth case is the closest to the experimentally measured value for the point repered by the intersection of the planes defined by $\mathrm{x}=50 \mathrm{~mm}, \mathrm{y}=50 \mathrm{~mm}$ and $\mathrm{z}=100 \mathrm{~mm}$. Also, it has been observed that the time resolution increases with the decrease of the size of mesh cells. Later in the work, it is proposed to use the fifth mesh. This choice leads us to a better result with regards to the precision and the spent time.

Figure 8 shows the different profiles of the average velocity for 
Citation: Driss Z, Chelbi T, Barhoumi W, Kaffel A, Abid MS (2015) Numerical and Experimental Investigations on the Meshing Model Choice of a NACA2415 Airfoil Wind Turbine Placed in an Open Wind Tunnel. J Phys Math 6: 141. doi:10.4172/2090-0902.1000141

different cells size. It presents the superposition of the numerical results gathered from the software "Solid works Flow simulation" and the experimental results taken by the anemometer. The velocity profiles are chosen for different directions situated in the test section. The considered directions are defined by the intersection of the plane $\mathrm{x}=0 \mathrm{~mm}$ with the planes $\mathrm{z}=50 \mathrm{~mm}, \mathrm{z}=100 \mathrm{~mm}, \mathrm{z}=150 \mathrm{~mm}$ and $\mathrm{z}=-150$ $\mathrm{mm}$. The different velocity profiles seem to have the same appearance. However, the velocity values depend on the cell size. Indeed the greater the cell size gets the more the gap between numerical and experimental results is large. The best result regarding precision and time is found to be a cell of $5 \mathrm{~mm}$ size. In this case, the gap is about $4 \%$. Regarding to these results, the numerical model can predict the aerodynamic results with a good agreements.

\section{Conclusion}

In this work, we are interested on the study of the meshing effect on the numerical results of a horizontal axis wind turbine with a NACA2415 airfoil type. Particularly, we have changed the cells size and we have compared the numerical results with the values of the velocity collected experimentally from an open wind tunnel to choose the adequate numerical model. The different velocity profiles seem to have the same appearance. However, the velocity values depend on the cell size. Indeed the greater the cell size gets the more the gap between numerical and experimental results is large. The best result regarding precision and time is found to be a cell of $5 \mathrm{~mm}$ size. In the future, we intend using the particle image velocimetry laser (PIV) system to determine the local characteristics.

\section{References}

1. Hirahara H, Hossain MZ, Kawahashia M, Nonomura $Y$ (2005) Testing basic performance of a very small wind turbine designed for multi-purposes. Renewable Energy 30: 1279-1297.

2. Wrigh AK, Wood DH (2004) The starting and low wind speed behaviour of a small horizontal axis wind turbine. Journal of Wind Engineering and Industrial Aerodynamics 92: 1265-1279.
3. Schreck SJ, Robinson MC (2007) Horizontal Axis wind turbine blade aerodynamics in experiments and modeling. IEEE Transactions on Energy Conversion 22: 61-70.

4. Mirzaei M, Ardekani MA, Doosttalab M (2009) Numerical and experimental study of flow field characteristics of an iced airfoil. Aerospace Science and Technology 13: 267-27.

5. Hu D, Hu O, Du Z (2006) A study on stall-delay for horizontal axis wind turbine. Renewable Energy 31: 821-836.

6. Sicot C, Devinant P, Loyer S, Hureau J (2008) Rotational and turbulence effects on a wind turbine blade: investigation of the stall mechanisms. Journal of Wind Engineering and Industrial Aerodynamics 96: 1320-1331.

7. Tahar Bouzaher M (2014) Numerical study of flow separation control over a NACA2415 airfoil, world academy of science, engineering and technology. International Journal of Mechanical, Aerospace, Industrial and Mechatronics Engineering 8: 782-785.

8. Driss Z, Damak A, Karray S, Abid MS (2012) Experimental study of the internal recovery effect on the performance of a Savonius wind rotor. Research and reviews: Journal of Engineering and Technology 1: 15-21.

9. Damak A, Driss Z, Abid MS (2013) Experimental investigation of helical Savonius rotor with a twist of $180^{\circ}$. Renewable Energy 52: 136-142.

10. Driss Z, Mlayeh O, Driss D, Maaloul M, Abid MS (2014) Numerical simulation and experimental validation of the turbulent flow around a small incurved Savonius wind rotor. Energy 74: 506-517.

11. Frikha S, Driss Z, Hagui MA (2015) Computational study of the diffuser angle effect in the design of a waste heat recovery system for oil field cabins. Energy 84: 219-238.

12. Mabrouki I, Driss Z, Abid MS (2014) Numerical Study of the hydrodynamic structure of a water savonius rotor in a test section. Jordan Journal of Mechanical and Industrial Engineering 8: 127-136.

13. Chtourou W, Ammar M, Driss Z, Abid MS (2014) CFD prediction of the turbulent flow generated in stirred square tank by a rushton turbine. Energy and Power Engineering 6: 95-110.

14. Ammar M, Chtourou W, Driss Z, Abid MS (2011) Numerical investigation of turbulent flow generated in baffled stirred vessels equipped with three different turbines in one and two-stage system. Energy 36: 5081-5093.

15. Driss Z, Bouzgarrou G, Chtourou W, Kchaou H, Abid MS (2010) Computationa studies of the pitched blade turbines design effect on the stirred tank flow characteristics. European Journal of Mechanics B/Fluids 29: 236-245. 